\title{
Obligaciones de las personas morales
}

\author{
Obligations of Moral Persons
}

Luis A. Pérez-Granados ${ }^{a}$, Beatriz Sauza-Ávila ${ }^{b}$ Claudia B. Lechuga-Canto ${ }^{c}$

\begin{abstract}
:
One of the most important challenges in our country in tax matters, is the aspect of clearly understanding the regulations, to illustrate in a simple way the conceptual map related to the obligations of the legal entities is presented in accordance with article 76 of the Law of the Income Tax, it will find some terms that are useful and important to know to comply in time and form with tax obligations, for the benefit of our country to make the timely payment of taxes and to be used for the good of the citizenship.
\end{abstract}

Keywords:

Legal entities, Income Tax Law, obligations

\section{Resumen:}

Unos de los retos más importantes en nuestro país en materia fiscal, es el aspecto de entender con claridad la normativa, para ilustrar de manera sencilla se presenta el mapa conceptual relacionado con las obligaciones de las personas morales de acuerdo al artículo 76 de la Ley del Impuesto Sobre la Renta, en él se encontrarán algunos términos que son útiles e importantes conocerlos para cumplir en tiempo y forma con la obligaciones tributarias, en beneficio de nuestro país al realizar el pago oportuno de los impuestos y al ser estos utilizados en bien de la ciudadanía..

Palabras Clave:

Personas morales, Ley del Impuesto Sobre la Renta, obligaciones

\section{Introducción}

Según datos reportados por Córdova (2016), en el periódico el economista, México es el cuarto país con menores cargas fiscales, siendo este punto de vista a nivel mundial, sin embargo; debido a la complejidad de la interpretación de las leyes fiscales mexicanas, es necesario que todos los que se encuentren en alguna situación jurídica o de hecho, conozcan de manera clara y concisa lo que deben cumplir en materia tributaria, para con ello efectuar con lo establecido en el artículo 32 fracción IV de la Constitución Política de los Estados Unidos Mexicanos, al establecer que se debe contribuir al gasto público de manera proporcional y equitativa que dispongan las leyes, es por este motivo que se elaboró un mapa conceptual, el cuál muestra las obligaciones de las personas morales establecidas en el artículo 76 de la Ley del Impuesto Sobre la Renta.

\section{Obligaciones de las personas morales}

El mapa presenta las obligaciones que las personas morales tienen en materia fiscal, entiéndase por persona moral la unión de dos o más personas físicas que se unen con la finalidad de constituirse en una empresa, estas obligaciones están reguladas en el artículo 76 de la Ley del Impuesto Sobre la Renta. En él se muestran algunos términos que son

\footnotetext{
Autor de Correspondencia, Universidad Autónoma del Estado de Hidalgo, Escuela Superior de Ciudad Sahagún luisangel.uaeh@gmail.com.mx. 
útiles e importantes conocerlos para cumplir en tiempo y forma con la obligaciones tributarias, como lo es el de llevar contabilidad de acuerdo a lo establecido en el Código Fiscal de la Federación, efectuando los registros contables correspondientes, la obligación de expedir comprobantes fiscales de acuerdo a las actividades que realice, presentar declaración anual del Impuesto Sobre la Renta así como declaraciones informativas, formular los estados financieros de la entidad, llevar un control de inventarios, informar a las autoridades fiscales de diversas transacciones monetarias.

En conclusión, las personas morales deben cumplir estrictamente con las disposiciones fiscales, su desconocimiento no los exime de su cumplimiento, por esta razón es necesario que conozcan sus obligaciones para poder efectuar en tiempo $\mathrm{y}$ forma con el pago oportuno de sus impuestos.

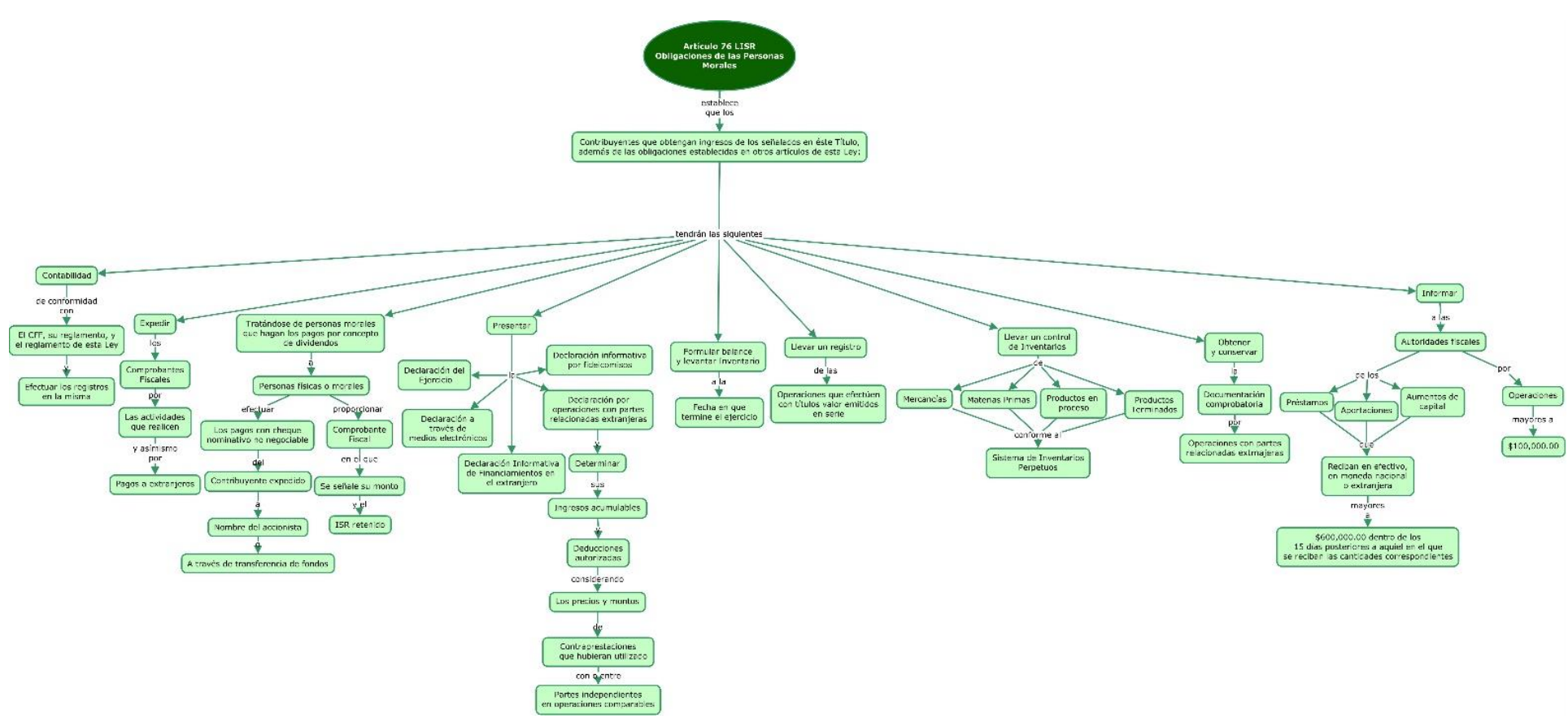

Figura 1Figura 1. Obligaciones de las personas morales

\section{Referencias}

[1] Córdova, Y. (2016), México es el cuarto país con menor carga fiscal. Economista, consultada en: https://www.eleconomista.com.mx/economia/Mexicoes-el-cuarto-pais-con-menor-cargas-fiscales-KPMG-20161010-0142.html

[2] Cámara de Diputados del H. Congreso de la Unión, (2018), Ley del Impuesto Sobre la Renta, Diario Oficial de la Federación, 1 de enero de 2018, Ciudad de México.

[3] Osorio, Y. (2014), Facultades de las Autoridades Fiscales, consultada en https://prezi.com/lcgenotbjxoh/facultades-de-las-autoridades-fiscales/.

[4] Martínez, J.A. (2013), Análisis a las facultades de las Autoridades Fiscales, consultada en https://prezi.com/0_jm8y9_mumx/81-analisis-a-las-facultadesde-las-autoridades-fiscales/?webgl=0

[5] Congreso de la Unión (2017), Constitución Política de los Estados Unidos Mexicanos, consultada en: http://www.diputados.gob.mx/LeyesBiblio/pdf/1_150917.pdf 